\title{
GEOGRAFIA DO COTIDIANO: O ENSINO DOS CONTEÚDOS GEOGRÁFICOS MEDIANTE A TÉCNICA DA TEMPESTADE DE IDEIAS
}

\author{
Everyday geography: the teaching of geographic content through the technique of the storm of \\ ideas
}

\section{Geografía cotidiana: la enseñanza del contenido geográfico a través de la técnica de la tormenta de ideas}

Cícero Antonio Jatanael da Silva Tavares ${ }^{1}$ http://orcid.org/0000-0002-2219-7727

\footnotetext{
${ }^{1}$ Graduado em Geografia pela Universidade Regional do Cariri - URCA - Crato - Ceará - Brasil, jatanael.s@gmail.com
}

\section{Resumo}

Este artigo aborda sobre o uso da tempestade de ideias no ensino de Geografia. Essa técnica é de origem paradidática e ao adequá-la para o ensino, é permitido usá-la com os alunos, despertando seus interesses pelos conteúdos mediante problematizações referentes a seus cotidianos e a eventos externos aos seus espaços vividos, desde que abarquem os seus saberes. Assim, esteve proposto a verificação da eficiência desse recurso quanto a essa função pedagógica. Mediante a prática realizada, cabe efetivar a sua aplicação ao identificar que os alunos se tornaram mais participantivos nas aulas e, consequentemente, aprenderam os conteúdos.

Palavras-chave: Ensino. Geografia. Tempestade de ideias.

\begin{abstract}
This article discusses the use of the storm of ideas in teaching geography. This technique has a paradidatic origin and by adapting it to teaching, it is allowed to use it with the students, arousing their interest in the contents through problematization regarding their daily lives and events external to their lived spaces, as long as they include their knowledge. Thus, it was proposed to verify the efficiency of this resource regarding this pedagogical function. Through the practice, its application is effective by identifying that the students became more participative in the classes and, consequently, learned the contents.
\end{abstract}

\section{Keywords:}

\section{Resumen}

Este artículo analiza el uso de la tormenta de ideas en la enseñanza de la geografía. Esta técnica es de origen paradidatica y al adaptarla a la enseñanza, se permite usarla con los estudiantes, lo que despierta su interés en los contenidos a través de la problematización con respecto a sus vidas diarias y eventos externos a sus espacios de vida, siempre que incluyan sus conocimientos. Por lo tanto, se propuso verificar la eficiencia de este recurso con respecto a esta función pedagógica. A través de la práctica, su aplicación es efectiva al 
identificar que los estudiantes se volvieron más participativos en las clases y, en consecuencia, aprendieron los contenidos.

Palabras clave: Enseñanza. Geografía. Tormenta de ideas

Recebido em: 24/09/2019

Aceito para publicação em: 29/11/2019

\section{Introdução}

Este artigo tem por objetivo a realização de um relato de experiência sobre o uso da técnica "tempestade de ideias" aplicada no ensino. A saber, foi visada a averiguação da efetividade desse recurso com os discentes no tocante as suas participações em debates nas aulas e, consequentemente, em suas aprendizagens dos conteúdos da disciplina de Geografia. "Brainstorming", como também é conhecida, é uma técnica paradidática proposta para atrair grupos em geral aos debates. Consiste sucintamente em levantar o maior número possível de opiniões perante aos envolvidos sobre um determinado assunto, para que então seja iniciada uma ampla discussão propondo fazer uma seleção com as melhores alternativas (MAZZOTTI; BROEGA; GOMES, 2012, p. $3)$.

Apropriando esse atributo para o ensino, pode-se mediar de maneira semelhante os conteúdos da Geografia, excetuando a fase de filtração de opiniões, uma vez que na educação é viável o aproveitamento da pluralidade de concepções proferidas. Dessa forma, a tempestade de ideias se promove desde os primeiros minutos de aula, quando o professor deve problematizar a temática a ser intermediada e levantar informações preliminares correlatas aos cotidianos dos alunos, e se estende durante toda a atividade.

Nesse sentido, diagnostica-se que as abordagens da Geografia sob os olhares discentes e as suas respectivas realidades têm trilhado por caminhos opostos, uma vez que uma parcela considerável destes não consegue aplicar o conhecimento geográfico adquirido em suas rotinas diárias. De tal forma, compreendem a matéria escolar como uma mera componente curricular em que a única motivação para a estudar sejam as suas aprovações no final do ano letivo. Dentre uma série de fatores, é elencado que esse episódio se promove comumente devido a mediação docente ocorrer de modo distinto daquilo que é de interesse dos estudantes.

A aplicação desse recurso perpassa quanto ao fato de os alunos desenvolverem a capacidade de compreenderem a disciplina de uma maneira que saibam relacionar com os seus cotidianos. Tal atividade viabiliza circunstâncias como a probabilidade de 
despertar as suas curiosidades pelas temáticas, ao ser tratada de modo que os próprios se sintam integrados na abordagem, em razão do educador realizar a mediação em associação aos espaços vividos ou a fatores externos supostamente de conhecimento e interesse dos educandos, reconhecidos através da mídia. Assim, tal motivação contribui para que estes identifiquem a relevância da Geografia em suas formações.

A tempestade de ideias pode ser inserida também em turmas concebidas pelo docente como aquelas em que não estejam devidamente interessadas ou confortáveis a participarem das discussões. Com o uso desse artificio, ocorre a possibilidade de instigá-los aos debates dos conteúdos e consequentemente contribuir ainda para a aprendizagem significativa do que se está estudando. Portanto, perpassa ao professor o papel de atrair os alunos para a aula. Conforme destaca Avelar (2014, p. 84), é meditado que para ocorrer o interesse e, consequentemente a aprendizagem, os discentes necessitam receberem estímulos externos, onde caso contrário tenderá a permanecerem inertes.

Compreendendo a utilidade de um eficiente planejamento metodológico, almejando contemplar os objetivos ora supramencionados, a construção deste trabalho se assenta em duas fases centrais: levantamentos bibliográficos e empíricos. No tocante à teoria, fez-se a passagem por leituras pertinentes. No que concerne a prática, resultouse do desenvolvimento de aulas de Geografia, em uma escola de ensino médio, em Juazeiro do Norte/CE.

Mediante ao que se pode averiguar ao longo deste manuscrito, é denotado a relevância de uma discussão referente aos supracitados fatores adversos que englobam o ensino da Geografia. Abre-se também a probabilidade de outros professores realizarem a aplicação da tempestade de ideias em suas aulas, uma vez que as problemáticas evidenciadas neste recorte espacial tendem a estarem presentes em outras extensões escolares.

\section{Procedimentos metodológicos}

Este trabalho possui uma natureza tanto teórica quanto empírica. Para que fosse alcançada à empiria, fez-se imprescindível a passagem por leituras pertinentes que viabilizassem o conhecimento dessa técnica para então aplicá-la no ensino. A saber, visou-se analisar a efetividade desse recurso paradidático quando aplicado intencionalmente na comunidade escolar. 
A princípio, foi processado as leituras bibliográficas conexas a essa abordagem. Cabe enfatizar que devido a tempestade de ideias não ser frequentemente trabalhada pela comunidade científica do ensino de Geografia, as obras publicadas são escassas. Contanto, ressalta-se que autores como Mazzotti, Broega, Gomes (2012), Cavalcanti (2010) e Freire (1996) contribuíram para o desenvolvimento deste trabalho.

Realizado os procedimentos teóricos, viabilizou-se ser adentrada a etapa seguinte. Dessa forma, foi praticada a inserção desse recurso no ensino. A sua aplicabilidade se deu em uma escola pública, em Juazeiro do Norte. Detalhadamente, em duas turmas de $1^{\circ}$ ano do ensino médio, na disciplina de Geografia. A seleção por essa instituição ocorreu em razão de sua acessibilidade, bem como pela maior liberdade e tempo disponibilizado.

Assim, fez-se necessário o uso de 8 horas/aulas em cada uma das turmas. É salientado ainda que o tempo para essa experiência ocorreu de maneira desmembrada, sendo este prazo distribuído ao longo das semanas, respeitando o horário programado das matérias escolares durante o ano letivo.

O uso da "tempestade de ideias" é inteiramente teórico, tornando-a viável quando pensado sobre necessitar ser feito investimentos financeiros. A concretização dos objetivos deste trabalho ocorreu precisamente através de entrevistas semiestruturadas, sendo efetuada uma análise referente ao comportamento dos alunos durante a atividade. Com isso, a sua aplicação diante da turma perpassou coletivamente.

De tal modo, é destacado que por conta da adoção desse recurso técnico para a obtenção dos dados ambicionados e por não adotar o uso de gráficos e tabelas, o produto final dessa experiência pedagógica está dissolvido de modo contextualizado perante o tópico correlato aos resultados.

Diante do que esteve proposto quanto aos procedimentos metodológicos e aliado aos resultados adquiridos na aplicação dessa técnica, é ressaltado que os caminhos percorridos para a consolidação desse atributo foram executados com sucesso, conforme pode ser identificado ao longo deste manuscrito.

\section{Reflexões sobre a tempestade de ideias no ensino de Geografia}

A disciplina de Geografia é uma das componentes da área de humanas na matriz curricular educacional, conforme aponta os Parâmetros Curriculares Nacionais - PCNs. 
Em âmbito escolar, essa ciência enfatiza a formação de alunos críticos e participativos no meio social em que convivem.

Segundo Silva (2016, p. 17), é por meio de conceitos geográficos, como os de região, território, lugar e paisagem, que o docente constrói uma didática que contribua para a compreensão da relação homem e natureza e dos próprios indivíduos entre si. Com isso, viabiliza que os discentes entendam como se desenvolve a organização socioespacial.

Contanto, constata-se que há entre os educandos uma disparidade quanto a significância percebida dos conteúdos da Geografia. Por vezes, devido os educadores mediarem as aulas com abordagens atípicas, os estudantes não conseguem identificar a necessidade de estudá-lo, acreditando na irrelevância da temática e assim refletindo diretamente na construção de uma percepção incongruente no tocante a importância do conhecimento geográfico (CAVALCANTI, 2010, p. 3).

Desse modo, encarrega-se ao professor a tarefa de saber manejar as temáticas de uma forma em que consiga reverter esse empecilho. Nessa direção, perpassa a utilização de diversas metodologias em suas mediações. Logicamente, por causa das condições ínfimas ofertadas pelo governo local, os educadores não possuem todos os materiais didáticos que desejam, todavia compete a este profissional da educação o desejo de proporcionar a aprendizagem significativa de seus alunos. Nesse seguimento, é buscado a utilização de meios alternativos e viáveis em termos econômicos. Inúmeras técnicas de ensino nesse quesito podem ser inseridas no contexto educacional, de tal forma que contribua para a construção de bons resultados na aprendizagem dos discentes.

Mediante a essa perspectiva financeira surge a tempestade de ideias. Esse recurso é de origem paradidática, portanto, não foi elaborado visando especificamente a comunidade escolar. É uma técnica criada por Alex Osborn, em 1939, que está associada a criatividade e inserida, geralmente, no planejamento de projetos do ramo do empreendedorismo, direcionando a solução de adversidades, através da problematização de ideias (MAZZOTTI; BROEGA; GOMES, 2012, p. 3).

A técnica de brainstorming é utilizada com a finalidade de gerar o maior número de ideias possíveis acerca de um determinado tema ou questão. $\mathrm{O}$ exercício tradicional propõe que um grupo de pessoas, preferencialmente de áreas e competências diferentes, se reúnam a fim de colaborar para uma "tempestade de ideias", onde as diferenças e experiências de uma somadas e associadas às dos outros, formem um longo processo de sugestões e discussões. Nenhuma ideia é 
inicialmente descartada ou julgada, todas as ideias são ouvidas e anotadas, para que possam evoluir até à chegada da solução efetiva. (MAZZOTTI; BROEGA; GOMES, 2012, p. 3).

Assim, por ser um procedimento utilizado em grupo, objetiva a coleta do maior número possível de ideias, sem fazer críticas ou julgamentos, em um primeiro momento. Posteriormente, após ser concluída a exposição de todas as opiniões do coletivo, é realizado as análises, propondo a cada um dos envolvidos a busca pelo convencimento aos demais colegas de que a sua argumentação é a mais viável, sendo essa a fase final na filtração de ideias para se chegar a uma solução (NÓBREGA; LOPES NETO; SANTOS, 1997, p. 249).

Adaptando para o ensino, a tempestade de ideias consiste primeiramente no sentido de gerar avaliações diagnósticas com os alunos. Antes de cada aula, é preciso ser elaborado problematizações que despertem a curiosidade dos estudantes. Com isso, faz-se questionamentos antecipados sobre o que os educandos conhecem a respeito do tema que será abordado, para que posteriormente sejam inseridas informações conexas.

Elaborado a análise avaliativa daquilo que os alunos conhecem preliminarmente, o professor mediará o conteúdo tendo como ponto de partida as ideias incluídas pelos estudantes para então ser dada ênfase ao que foi percebido com maior dificuldade, propiciando a expansão de suas aprendizagens após conseguir atraí-los para o debate do conteúdo. Por exemplo, se em uma eventual aula for mediado sobre a industrialização do Brasil, acredita-se que estes tenham noções prévias do que se trata essa abordagem, devido as suas vivências tanto no ambiente escolar quanto na sociedade em geral, por ser meio que os propiciam a acumulação de informações correlatas. Dessa maneira, compete ao docente dar a liberdade para que os envolvidos na atividade exponham seus conhecimentos em esboços, e assim este mediador possa gerenciar a possibilidade de os discentes ampliarem os seus respectivos saberes.

Ao praticar a técnica, primeiramente se faz necessário a aplicação de inquietações perante aos alunos. Assim, é proferido problematizações que perpassem o sentido de contribuir para que estes reflitam sobre a importância do conhecimento geográfico, o papel desempenhado por essa ciência na dimensão socioespacial e, sobretudo, a identificação autônoma de aspectos da Geografia em seus cotidianos.

A tempestade de ideias abarca uma série de fatores interligados e que contribuem para a obtenção de resultados positivos na aprendizagem. Além da conotada avaliação diagnosticada, serve também como um meio estimulante da curiosidade dos 
estudantes pelo assunto ministrado. Isso ocorre a partir do momento em que o professor perpassa a citar exemplos presentes da localidade que estejam em consonância com a temática abordada.

De tal forma, destaca-se que embora se busque trabalhar com os espaços vividos dos alunos, por meio da "tempestade de ideias" ainda é viável abordar sobre temas externos ao contato rotineiro da comunidade escolar, de tal forma que estejam inclusos em seu rol de informações acumuladas, como é o caso de episódios provavelmente reconhecidos através de meios midiáticos mediante as repercussões em suas diversas escalas, sejam estas local, regional, nacional e/ou internacional.

Para ambas as situações supracitadas, por conta dos alunos se sentirem inclusos em uma determinada temática, propendem a mostrarem interesses pela ampliação de seus conhecimentos. Exemplo prático pode ser dado quando ocorre uma mediação referente a urbanização. Ao ser apropriado a essa abordagem em uma escala reconhecida perante aos discentes, estes conseguem recordar alguns aspectos que contribuem na organização socioespacial da geografia urbana da determinada cidade. Dessa forma, tendem a se empenharem nas participações das discussões geográficas, mostrando as suas conexas experiências, bem como as possíveis soluções aos problemas percebidos (LIMA; THOMAZ, 2011, p. 20).

Em consonância com a presente perspectiva, cabe destacar reflexões que apontam para a relevância desse artificio. Dentre estas, enfatiza-se a seguinte inquietação: será que o interesse dos estudantes pela Geografia seria idêntico em duas eventuais situações distintas, onde em uma a abordagem seja em uma escala global enquanto que a outra ocorra em escala local? Através das abordagens aqui levantadas, afirma-se que haja reações divergentes.

De tal modo, faz-se a seguinte ponderação: em uma casual aula sobre Hidrografia, por exemplo, qual seria a percepção dos educandos sobre a necessidade de conhecimento geográfico em escala global para a sua formação, como em situações que destacam as características de rios europeus, como o Volga, Reno e Danúbio? É uma importante inquietação a ser levantada.

Enquanto isso, convertendo essa situação para uma escala local: a aula sendo mediada a partir de rios presentes na região vivenciada pelos alunos ou de cursos de água que se encontrem em outras extensões, mas que sejam de ciência prévia da turma, será que haveriam maiores interesses pelo conteúdo? É ressaltado que sim, uma vez que 
a partir do momento que os educandos estudam temáticas referentes aos seus alcances preconcebidos, tendem a buscarem conhecer mais sobre as suas características.

Nesse sentido, é preciso ser reforçado que primeiramente se faça abordagens trazendo questões em escalas locais, sendo inseridas em casos excepcionais as situações externas que são de saberes dos discentes, quando não for possível elencar eventos vivenciados.

Em harmonia com essa argumentação supratranscrita, Cavalcanti (2010, p. 6) realça que:

Trabalhar esses fenômenos como conteúdo geográfico é compreendêlos a partir do lugar do sujeito, de sua realidade, o que permitiria maior identificação dos alunos com os conteúdos. O lugar deve ser referência constante, levando ao diálogo com os temas, mediando a interlocução e a problematização necessária à colocação do aluno como sujeito do processo. Ao estudar o lugar, pode-se atribuir maior sentido ao que é estudado, permitindo que se façam relações entre a realidade e os conteúdos escolares.

Nessa linhagem, é preciso que o docente insira exemplares da temática que estejam correlatas as realidades dos estudantes, proporcionando a estes as percepções de se perceberem como integrantes da abordagem em questão e sobretudo identificarem que as compreensões adquiridas diante da Geografia são aplicáveis na sociedade, deixando, assim, de a conceber como uma disciplina irrelevante.

É importante frisar também que os conhecimentos em escalas globais, como esses referentes aos principais rios europeus, são essenciais. Contanto, ao professor compete a função de saber manejar de uma maneira que torne o conteúdo atrativo, trazendo essas ocasiões para a existência de fatos conhecidos pelos alunos. Cabe destacar ainda que o global e o local são escalas complementares.

A abordagem multiescalar tem como suporte o entendimento da necessária articulação dialética entre escalas locais e globais na construção de raciocínios espaciais complexos, como se requer hoje para o entendimento da realidade. O global, visto como conjunto articulado de processos, relações e estruturas do espaço tem um significado específico e peculiar em cada lugar; mas esse lugar não pode ser apreendido completamente se não se fizer uma articulação de seu significado com a totalidade da qual faz parte. Busca-se entender os fenômenos na relação parte/todo, concebendo a totalidade dinâmica, no jogo de escalas. Se no item anterior enfatizou-se a referência necessária ao lugar e à realidade vivida pelo sujeito, aqui se destaca a indicação de abordar os conteúdos buscando explicações, 
causas, motivos, não apenas no local, mas em outras escalas de análise (CAVALCANTI, 2010, p. 6-7).

Adentrando a discussão, constata-se que compete ao educador o papel de construir conhecimentos, e não a função de transferir. Ao entrar em sala de aula, o professor deve estar aberto a indagações, a curiosidades, às perguntas dos alunos, a suas inibições, de maneira crítica e inquirida, sabendo que a função é de ensinar e não a de transferir conhecimento (FREIRE, 1996, p. 21).

Esse destaque se dá por intermédio da percepção de que o mediador não transfere para os estudantes aquilo que sabe, como se estes não tivessem nenhuma sapiência antecipada do assunto. Ao docente compete a função de saber valorizar a percepção preconcebida dos discentes, e assim ajudá-los a desenvolverem esse rol de informações acumuladas.

O que se espera do professor de Geografia é o papel de saber cativar os alunos para que eles percebam que os aspectos geográficos estão presentes em seus respectivos cotidianos e que com o auxílio do mediador podem transformar os seus saberes, mesmo que de senso comum, em algo mais apurado. Com isso, o educador estará efetivamente construindo a aprendizagem dos educandos, e não meramente transmitindo conteúdos.

Conforme já destacado, o ensino da Geografia tem como propósito centralizador a formação de cidadãos ativos na sociedade, capazes de compreenderem que o estudo geográfico construído na comunidade escolar deve ser utilizado em outros ambientes perante as relações socioespaciais.

Portanto, surge a necessidade de o docente buscar a construção de saberes junto aos discentes de tal modo que viabilize a compreensão sobre a função social da Geografia. É preciso trazer problematizações dos cotidianos, sendo estas oriundas dos espaços vividos, bem como de fatos externos que presumidamente são de seus interesses, com o propósito de cativar a curiosidade dos alunos pela aprendizagem. Para tanto, requer a utilização da tempestade de ideias.

Com isso, é permitido adentrar em outra abordagem conexa. É preciso ressalta que além de possuir a compreensão pertinente aos conteúdos da Geografia, o professor também saiba intercedê-los. Na comunidade acadêmica, essa característica é compreendida como aquele que tem didática. Isto é, a situação em que este domina a disciplina, possui uma boa dicção e consegue mediar a aula eficientemente. Sendo, portanto, um educador que saiba contribuir efetivamente para o êxito dos envolvidos no 
processo de ensinoaprendizagem, conseguindo unir os seus estudos teóricos com a prática.

Em Libâneo (1992, p. 28), é possível compreender que:

\begin{abstract}
A didática se caracteriza como mediação entre as bases teóricocientíficas da educação escolar e a prática docente. Ela opera como que uma ponte entre o 'o que' e o 'como' do processo pedagógico escolar. A teoria pedagógica orienta a ação educativa escolar mediante objetivos, conteúdos e tarefas de formação cultural e científica, tendo em vista exigências sociais concretas; por sua vez, a ação educativa somente pode realizar-se pela atividade prática do professor, de modo que as situações didáticas concretas requerem o 'como' da intervenção pedagógica.
\end{abstract}

Desse modo, é permitido refletir sobre a qualidade do serviço docente, onde perpassa a necessidade de constantes qualificações, permitindo a este profissional a aptidão para exercer a função. Em harmonia com essa evidência, Tozetto (2017, p, 24543) constata que:

À medida que não se tem uma formação continuada que possibilite articular a teoria ao contexto prático, não é possível se ter um docente que atue na escola com qualidade. Quando a formação continuada fica só na transmissão de informações e não na construção de saberes que favoreçam a aquisição do conhecimento científico, deixa de propiciar um ensino no qual se forma um sujeito crítico, atuante na sociedade em que vive. Para que realmente se efetive uma formação continuada do docente que o considere como sujeito histórico, social, político e cultural, é preciso que esta se dê num movimento dialético de construção e de reconstrução da cultura e do conhecimento.

Tais circunstâncias concedem a abertura também para que seja viabilizada a noção do objeto de estudo da Geografia. Possuindo frequentes aperfeiçoamentos, o educador tende, a saber, mediar os conteúdos de modo que consiga facilmente relacionar ao que se encontram nos contextos vivenciados pelos discentes, propiciando a construção de conhecimento de modo propositivo e atrativo.

\title{
A prática da tempestade de ideias no ensino de Geografia
}

Aprofundando a presente discussão sobre a tempestade de ideias ao partir para a empiria, podem-se conhecer os resultados obtidos ante a aplicação dessa técnica no ensino de Geografia. A finalidade desse momento perpassou quanto ao entendimento 
sobre a efetividade desse artifício na mediação dos conteúdos dessa componente do currículo escolar.

A realização desse momento se deu em uma escola de ensino médio, em Juazeiro do Norte/CE. Especificamente, foi praticada com duas turmas de $1^{\circ}$ ano, onde foram efetivados os procedimentos metodológicos referentes ao comportamento dos alunos ao longo do uso dessa ferramenta.

Dessa maneira, um conjunto de problematizações se fizeram presentes durante a atividade, sendo inseridas conforme o andamento das aulas. Consideradas como aquelas de maiores significâncias, inicialmente estiveram inclusas as seguintes inquietações: Porque devemos estudar esse conteúdo? Qual a importância desse saber em nosso cotidiano? Conhece algum aspecto geográfico presente em sua comunidade?

Através da avaliação diagnosticada, observou-se que a princípio os alunos das referidas turmas estudavam as temáticas de modo mecanizado, sem compreenderem o sentido da ação. Ao serem questionados sobre o porquê de estudarem Geografia, em situações ínfimas foi exequível perceber uma noção do objeto de estudos dessa ciência. Com isso, uma parcela considerável da turma demostrou não compreender como se relacionava esse conhecimento com os seus respectivos cotidianos. Tal medida constatou-se também quando ao serem questionados sobre a identificação de acontecimentos de interesse da Geografia em seus espaços vividos, os próprios admitiram não terem percebidos casos correspondentes. Aqueles que minimamente conseguiam diagnosticar, não conseguiam efetuar explanações significativas sobre a situação.

Conforme observado, também foi diagnosticado que uma parcela considerável dos alunos percebe o ensino de Geografia de uma maneira deturpada, ao relatarem que as finalidades seriam a qualificação almejando o mercado de trabalho, bem como uma preparação para os vestibulares. Seus interesses perpassavam simploriamente ainda pelo fato de necessitarem atingir boas notas para serem aprovados na matéria escolar, não havendo inspirações particulares quanto as temáticas abordadas.

Preliminarmente, ainda se observou através dos primeiros momentos, bem como mediante diálogos com os professores dessa instituição de ensino, que as turmas envolvidas na atividade comumente são pouco participativas durante os debates.

Dessa forma, fez-se fundamental a inserção dessa técnica na mediação da Geografia. De início, foi percebida uma resistência dos alunos quanto as suas inclusões 
nas discussões em aula, mas conforme as atividades foram acontecendo, ocorreram progressos quanto aos objetivos dessa intervenção escolar.

Abordando sobre os conteúdos dissolvidos da Climatologia e Geomorfologia, ao longo do processo foi observado a existência de mudanças de comportamentos no tocante a participações e interesses nas aulas, conforme esteve sendo trabalhado a "tempestade de ideias". Isso se deu pelo fato dos educandos se sentirem integrantes dos temas ao ser dado ênfase a exemplos de situações geográficas que são reconhecidas.

No tocante a percepção sobre a relevância do conhecimento em suas vidas, foi elencado aspectos que despertaram a curiosidade dos alunos e os fizeram perceber que a Geografia está inteiramente presente em suas rotinas e assim se fazendo necessário a compreensão da disciplina. Uma das aulas em destaque embasou-se sobre as formas de relevo.

Ao iniciar a abordagem, foi dado exemplar da indispensabilidade de se conhecer a formação de relevo de uma localidade. Conforme supramencionado, embora parte dos acontecimentos não estejam diretamente vinculadas aos espaços vividos pelos discentes, podem ser inseridos acontecimentos que supostamente são de seus interesses e que se fazem presentes diante da internet e televisão.

Dentre os aspectos, deu-se destaque inicialmente a uma situação local, onde foi levantado a necessidade de se conhecer a geomorfologia das regiões com ocupações humanas, devido a possibilidade de ocorrer movimentos de massa. Tal situação esteve interligada a um episódio vivenciado pela população de uma cidade vizinha, onde o acontecimento ganhou repercussão regional.

Além desse caso, foi lançada ainda uma série de curiosidades, como uma que perpassou quanto a altimetria do relevo quando relacionada a outros aspectos da Geografia como a pressão atmosférica, que gera danos quando pessoas externas à essa condição espacial se inserem nesse ambiente. Nesse seguimento, foi desenvolvida junto aos estudantes uma reflexão sobre o porquê que quando clubes de futebol do Brasil vão disputar partidas em cidades como La Paz, capital da Bolívia, que evidencia uma altitude de mais de 3500 metros em relação ao nível do mar, alguns jogadores acaba tendo mal-estar.

Portanto, destaca-se que foram circunstâncias como as supracitadas que estiveram inseridas durante as atividades e que estimularam o desempenho dos alunos, contribuindo para que participassem mais dos debates ao exporem suas dúvidas, inquietações e compartilhando os conhecimentos de situações presentes em suas rotinas 
que englobam os estudos da Geografia. De tal modo, percebeu-se ante aos educandos que as participações e interesses pelos conteúdos aumentaram após a inserção da "tempestade de ideias", bem como foram ampliadas as suas cognições geográficas sobre os acontecimentos do dia a dia.

Dessa maneira, foi ocorrendo a aplicação desse recurso ao longo da mediação, visando reforçar também a abordagem daquilo que os estudantes apresentavam com maiores dificuldades de compreenderem. Para tanto, sempre trazendo acontecimentos reconhecidos pelos alunos, conforme percebido na aula sobre as formas de relevo.

É preciso ser ressaltado também que, caso expandido para outros espaços, os exemplos relacionados ao assunto a serem mencionados na atividade perpassam por critérios próprios, conforme o docente e os discentes forem inserindo indicações.

\section{Considerações finais}

Um dos grandes desafios no ensino é atrair os alunos para a aula, bem como fazê-los entenderem a importância das abordagens efetuadas. Assim, diversos procedimentos têm sido inseridos na educação, buscando romper com essa adversidade vigente.

Nesse sentido, diagnostica-se a necessidade dos professores se reinventarem e abordarem os conteúdos a partir de técnicas alternativas como a "tempestades de ideias", para viabilizarem a obtenção de aprendizagens satisfatórias aos educandos perante as temáticas da Geografia e, sobretudo fazê-los compreenderem a relevância do conhecimento geográfico em suas respectivas formações, possibilitando que exerçam papeis de cidadãos atuantes e entendedores do espaço que vivem.

Mediante o que se constatou na aplicação desse recurso paradidático com alunos de $1^{\circ}$ ano, em uma escola pública de Juazeiro do Norte, percebeu-se que esse artifício pode exercer um relevante papel no ensino de Geografia.

É preciso que técnicas como essa sejam maciçamente aplicadas na educação. Embora a sua criação não tenha sido direcionada a comunidade escolar, é uma ferramenta útil a esse ambiente. Contanto, é uma atividade que requer do docente, enquanto mediador, uma compreensão apurada do espaço geográfico, isso por conta que embora este procedimento seja exclusivamente teórico, requer saber manejá-lo para que seja viável interceder propositalmente os acontecimentos vinculados a essa ciência. 
Em linhas gerais, é possível admitir que, de fato, essa ferramenta tem se constituído de modo essencial no espaço escolar, e que através dela é viabilizado contornar as situações adversas que permeiam as participações dos alunos durante a aula, bem como as suas aprendizagens sobre os conteúdos da Geografia.

\section{Referências}

AVELAR, Alessandra Cândida. A motivação do aluno no contex to escolar. Anuário de produções acadêmico-científicas dos discentes da Faculdade Araguaia. Goiânia, v. 3, n, 1, p. 71-90, 2014. Disponível em: <http://www.faculdadearaguaia.edu.br/sipe/index.php/anuario/article/view/271/244> Acesso em: 15/09/2019.

CAVALCANTI, Lana de Sousa. A Geografia e a realidade escolar contemporânea: avanços, caminhos, alternativas. In: I seminário nacional: currículo em movimento perspectivas atuais. Anais... Belo Horizonte: UFG, 2010. p. 1-16. Disponível em: $<$ http://portal.mec.gov.br/index.php?option=com_docman\&view=download\&alias=716 7-3-3-geografia-realidade-escolar-lana-souza\&category_slug=dezembro-2010pdf\&Itemid=30192 > Acesso em: 12/09/2019.

FREIRE, Paulo. Pedagogia da autonomia: saberes necessários à prática educativa. $25^{\mathrm{a}}$ ed. São Paulo: Paz e Terra, 1996.

LIBÂNEO, José Carlos. Didática. São Paulo: Cortez, 1992.

LIMA, Janete Aparecida de; THOMAZ, Sérgio Luiz. O estudo do lugar e a formação do aluno cidadão. In: PARANÁ, Secretaria de Estado da Educação. O professor PDE e os desafios da escola pública paranaense: produções didático-pedagógica, 2008. Curitiba: SEED/PR., v. 2, 2011. (Caderno PDE). Disponível em: <http://www.gestaoescolar.diaadia.pr.gov.br/arquivos/File/producoes_pde/artigo_janete _aparecida_lima.pdf> Acesso em: 15/09/2019.

MAZZOTTI, Karla; BROEGA, Ana Cristina; GOMES, Luiz Vidal Negreiros. A Exploração da Criatividade, através do uso da técnica de brainstorming, adaptada ao processo de criação em moda. In: $1^{\circ}$ Congresso Internacional de Moda e Design $-1^{\circ}$ CIMODE. Anais... Guimarães/Portugal, 2012. p. 2970-2987. Disponível em: <https://core.ac.uk/download/pdf/55622453.pdf> Acesso em: 12/09/2019.

NÓBREGA, Maria de Magdala; LOPES NETO, Davi; SANTOS, Sergio Roberto dos. Uso da técnica de Brainstorming para tomada de decisões na equipe de enfermagem de saúde pública. Revista Brasileira de Enfermagem. Brasília, v. 50, n. 2, p. 247-256, abr./jun. 1997. Disponível em: 〈http://www.scielo.br/pdf/reben/v50n2/v50n2a09.pdf> Acesso em: 11/09/2019.

SILVA, Vânia Regina Jorge da. Os conceitos geográficos e sua importância na formação do professor para uma didática escolar. Revista Digital Simonsen. Rio de Janeiro, n. 4, 2016. Disponível em: 〈http://www.simonsen.br/revista-digital/wp- 
content/uploads/2016/06/45-Revista-Simonsen_N4-Vânia-Regina.pdf> Acesso em: 15/09/2019.

TOZETTO, Susana Soares. Docência e formação continuada. In: XIII Congresso Nacional de Educação. Anais... Curitiba, 2017. Disponível em:

$<$ https://educere.bruc.com.br/arquivo/pdf2017/23503_13633.pdf > Acesso em: 12/09/2019. 